\title{
Third Recurrence of Cardiac Myxoma in a Carney Complex Patient
}

\section{Terceira Recorrência de Mixoma Cardíaco em Paciente com Complexo de Carney}

\author{
David Alejandro Salazar Jaya¹, Kevin Rafael de Paula Morales , Félix Ramires , Paulo Sampaio Gutierrez¹, \\ Ricardo Ribeiro Dias ${ }^{1}$, Vagner Madrini Junior ${ }^{1}$ \\ ${ }^{1}$ Heart Institute of the University of São Paulo (InCor USP), São Paulo, SP, Brazil
}

\section{Introduction}

Primary cardiac tumors are an uncommon entity with an incidence of $0.3-0.7 \%{ }^{1}$ Most primary cardiac neoplasms are benign, with cardiac myxoma (CM) being the most prevalent type. ${ }^{2-3}$ Patients with $\mathrm{CM}$ may present symptoms due to embolic phenomena or intracardiac blood flow obstruction for which the treatment is surgical resection. ${ }^{4-5}$ Postoperative tumor recurrence occurs in up to $3 \%$ of cases; however, when myxomas are part of an underlying genetic syndrome, the recurrence rate can reach $22 \%{ }^{6}$ The main syndrome associated with this recurrence is the Carney complex $(\mathrm{CNC}){ }^{7}$ First described in 1985 by J. Aidan Carney, CNC is defined as an extremely rare autosomal dominant genetic syndrome with main clinical characteristics including skin pigmentation, heart myxomas, and endocrine neoplasms. ${ }^{8}$

\section{Case report}

A 44-year-old woman with a history of adrenalectomy 20 years prior for adrenocorticotropic hormone (ACTH)independent Cushing's syndrome in the context of primary pigmented nodular adrenocortical disease (PPNAD) and total thyroidectomy for thyroid carcinoma 19 years prior. At that time, facial lentiginosis lesions were identified; considering the associated findings described above, CNC was hypothesized. Transthoracic echocardiography (TTE) showed no evidence of intracardiac tumors, and her family history was unremarkable.

Ten years after being lost to follow-up, the patient returned with dyspnea on exertion. TTE showed a mass inside the right atrium (RA) with characteristics of atrial myxoma (AM) (Figure 1). The patient underwent surgical resection of the tumor, and histopathological analysis confirmed AM. Genetic testing due to the suspected $\mathrm{CNC}$ showed germline mutations in the PRKAR1A gene, corroborating the diagnosis.

The patient completed a two-year clinical follow-up, underwent a control TTE that showed a new AM, this time in the left atrium (LA), and underwent a new successful surgery. However, after the hospital discharge, she was lost to subsequent follow-up.

In February 2020, seven months after the last surgery, the patient was admitted to the emergency department for ischemic stroke that resulted in motor aphasia. In the

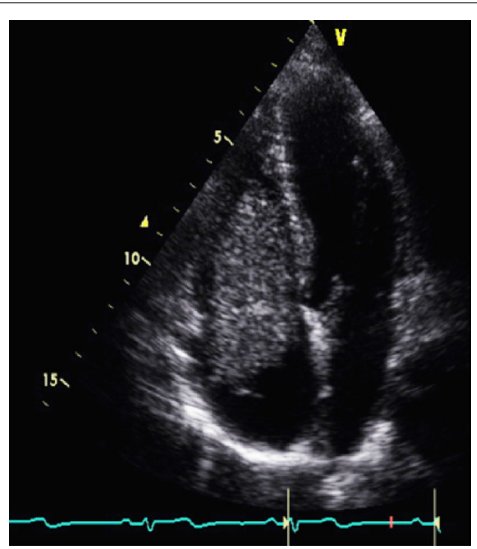

Figure 1 - Four-chamber transthoracic echocardiogram showing a mass in the right atrium, with heterogeneous content and irregular mobile surface, measuring up to $5.6 \times 4.0 \mathrm{~cm}$ in its largest diameter and projecting through the tricuspid valve into the right ventricle during diastole.

Keywords

Myxoma; Carney Complex; Echocardiography.

Mailing Address: David Alejandro Salazar Jaya •

E-mail: dasj_92@hotmail.com / david.salazar@hc.fm.usp.br

Manuscript received 9/12/2021; revised 10/31/2021; accepted 11/4/2021

DOI: $10.47593 / 2675-312 X / 20213404 e a b c 252$ 
etiological investigation, transesophageal echocardiography (TEE) showed a heterogeneous mass in the LA with irregular borders measuring approximately $0.8 \times 0.7 \mathrm{~cm}$ that adhered to the interatrial septum and was suggestive of AM (Figure 2).

Her case was evaluated and referred for hospital admission and surgical schedule for excision according to procedural availability. While waiting for surgery, the patient experienced a new ischemic stroke, which worsened the aphasia. TTE showed a significant mass increase in the LA to $3.0 \times 2.7 \mathrm{~cm}$ (Figure 3). Cardiac magnetic resonance imaging confirmed that the mass was located in the fossa ovalis (Figure 4). Therefore, the patient was referred for cardiac surgery for tumor removal and concomitant removal of the atrial septum, which was later reconstructed with a bovine pericardium patch.

The surgical notes reported no thrombi or other structures adhering to the surface of the tumor suggestive of an aggressive and fast-growing nature. The anatomical specimen was sent for anatomopathological analysis, which described a mass of gelatinous consistency measuring $3.3 \times 2.5 \times 1.5 \mathrm{~cm}$ and confirmed the diagnosis of AM (Figure 5).
On the fifth postoperative day, control TTE showed a preserved left ventricle ejection fraction (65\%) and no valve changes, thrombi, or pericardial effusion (Figure 6). The patient progressed clinically with stable vital signs and was discharged from the hospital.

\section{Discussion}

$\mathrm{CM}$ are infrequent, and $\mathrm{AM}$ recurrence cases are particularly rare; thus, in such cases, associated genetic syndromes should be suspected, especially $\mathrm{CNC} .{ }^{9}$ In this patient, it was possible to identify the $\mathrm{CNC}$ due to the presence of three major criteria (PPNAD, thyroid neoplasm, and CM) and one supplementary criterion (PRKAR1A gene mutation) (Table 1). Two-dimensional TTE is the ideal method for diagnosing MC, which classically shows a mobile myxoma connected to the interatrial septum by a narrow pedicle; this is the most relevant finding of suspected $\mathrm{CM}$. The main echocardiographic characteristics are heterogeneous echogenicity and occasional calcifications. The presence of a fixation pedicle allows the differentiation of $\mathrm{CM}$ from other masses. TTE findings are

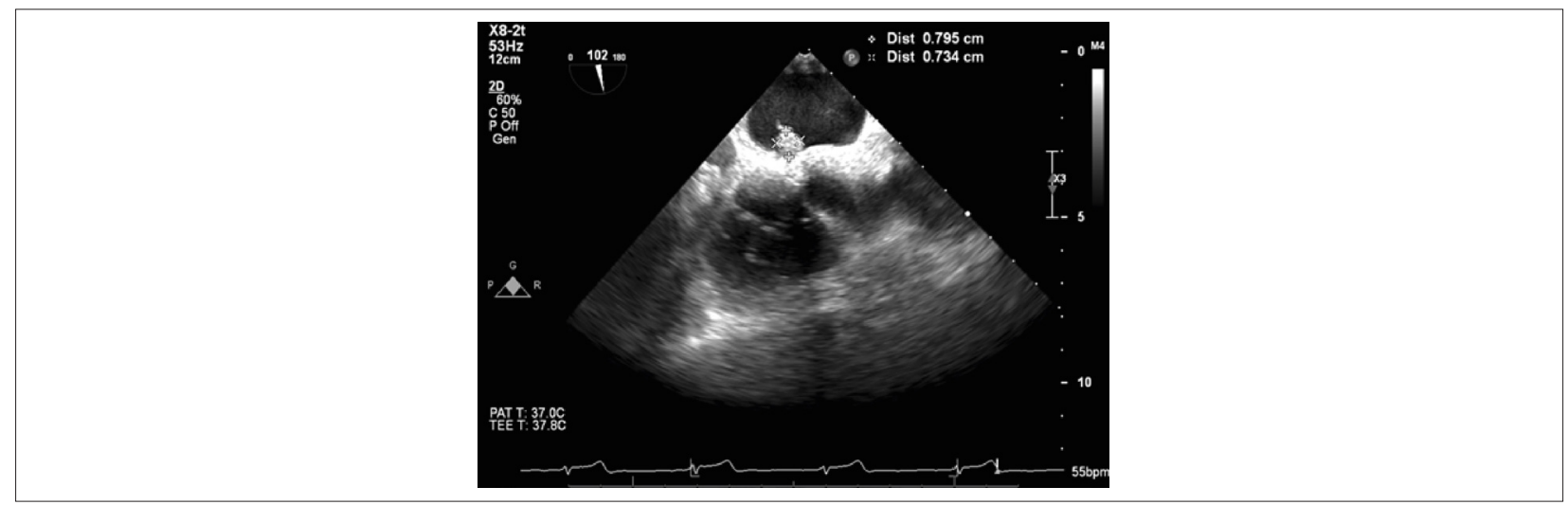

Figure 2 - Transesophageal echocardiogram showing an echogenic heterogeneous mass in the left atrium with irregular borders measuring approximately $0.8 \times 0.7 \mathrm{~cm}$ and adhered to the interatrial septum suggestive of cardiac myxoma.

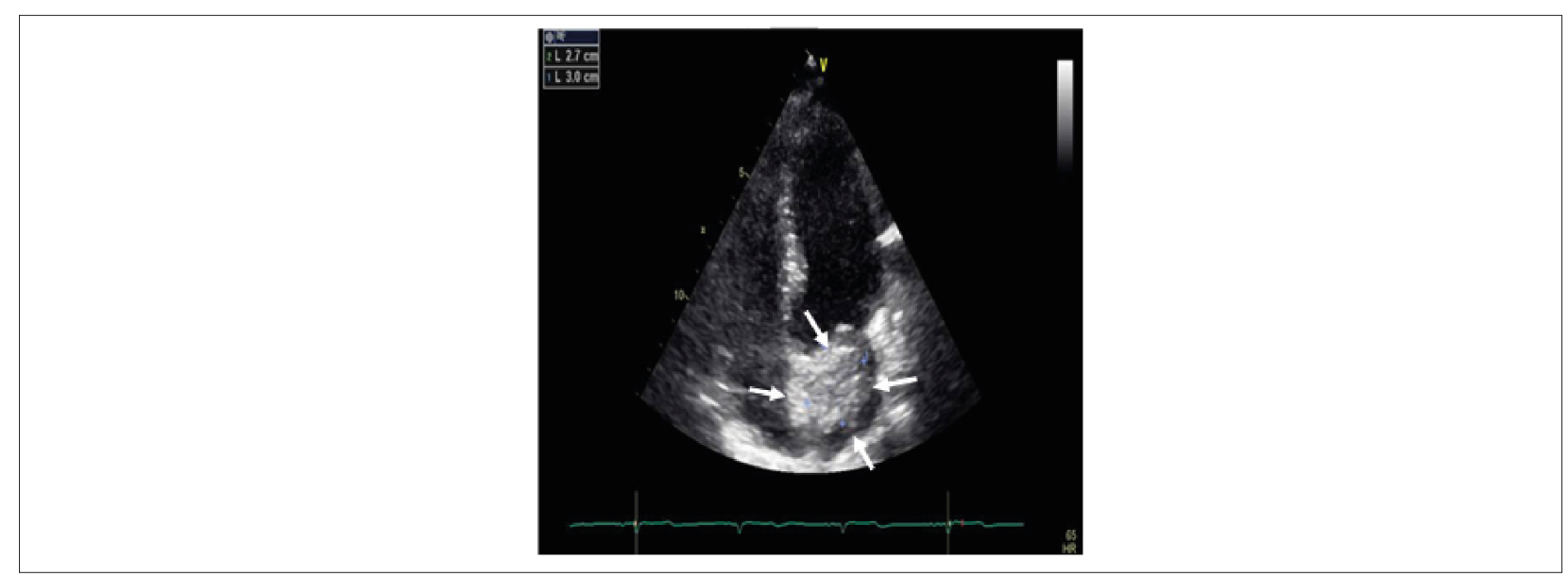

Figure 3 - Four-chamber transthoracic echocardiogram showing a hyperechogenic image with heterogeneous density located in the left atrium adherent to the interatrial septum with protrusion into the left ventricular inlet and measuring $3.0 \times 2.7 \mathrm{~cm}$ compatible with cardiac myxoma. 


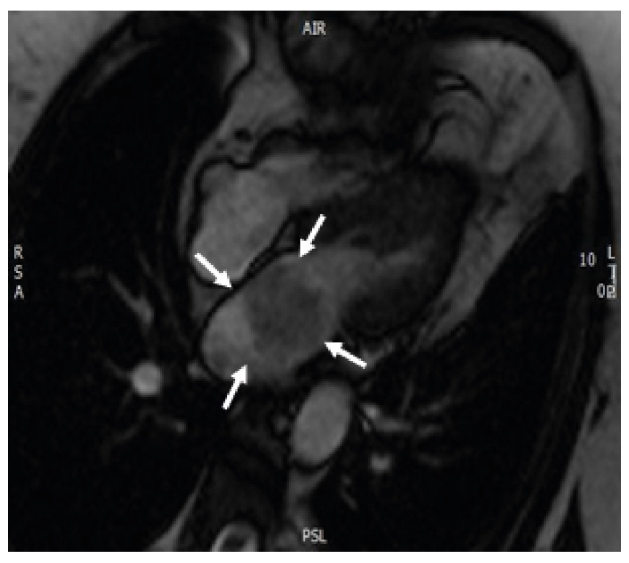

Figure 4 - Four-chamber cardiac magnetic resonance showing a left atrial mass implanted in the fossa ovalis region and projecting through the mitral valve measuring about $4.2 \mathrm{~cm}$ in its longest axis. High T1 and T2 signals, heterogeneous perfusion, and delayed enhancement with central low-signal areas are evident.

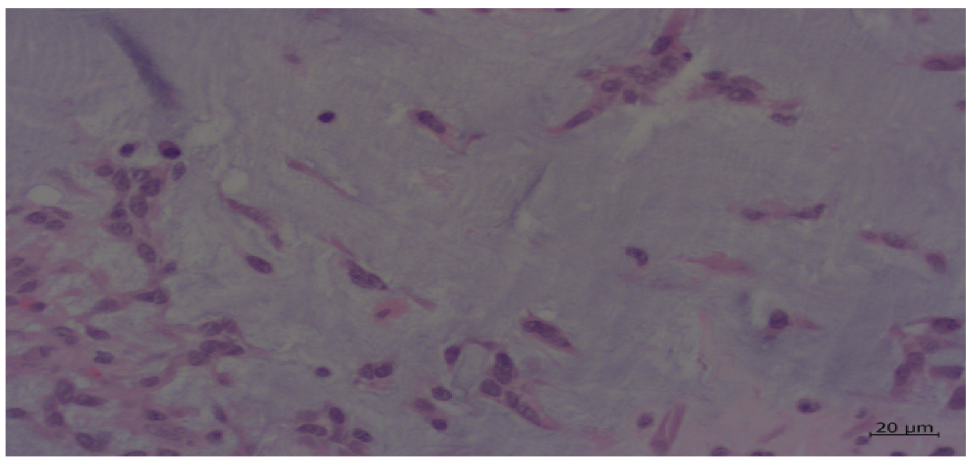

Figure 5 - Histological section of the tumor characterized by the presence of sparse elongated or stellate cells immersed in a myxoid matrix (slightly purplish). Hematoxylin and eosin staining (40x magnification).

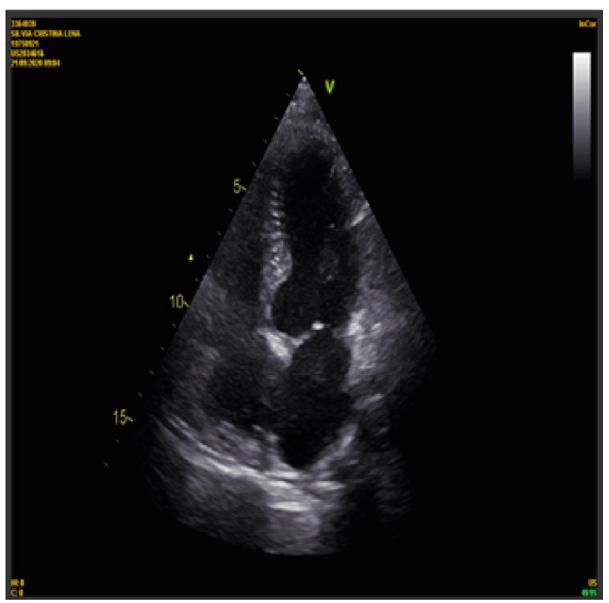

Figure 6 - Postoperative four-chamber transthoracic echocardiogram showing no masses, thrombi, or pericardial effusion. 


\section{Table 1 - Carney complex diagnostic criteria}

Skin pigmentation with typical distribution

Diagnostic criteria (major): $\quad$ (lips, conjunctiva, vaginal, and penile mucosa)

Myxomas (skin and mucosa)

Cardiac myxoma ${ }^{a}$

Breast myxomatosis ${ }^{\mathrm{a}}$ or magnetic resonance image suggestive of this diagnosis PPNADa

Acromegaly - growth hormone-producing adenoma $^{a}$

Calcified Sertoli cell tumor ${ }^{\mathrm{a}}$ or microcalcifications on testicular US

Thyroid neoplasm or multiple hypoechoic nodules on US

Melanotic schwannoma ${ }^{a}$

Multiple blue nevi

Ductal breast adenoma (multiple) ${ }^{a}$

Osteocondromixoma ${ }^{a}$

Supplementary criteria (minor): Affected first-degree relative

Inactivating PRKAR1a gene mutation

aHistologically confirmed. PPNAD, primary pigmented nodular adrenocortical disease; US, ultrasound.

usually sufficient for diagnosis, but if the results are suboptimal, TEE should be considered ${ }^{10}$. Histologically, CM contains multipotential mesenchymal cells that are able to differentiate into fibroblasts, smooth muscle cells, endothelial cells, and neuroendocrine cells, primarily within the atria and atrial septum. ${ }^{11}$ According to Edwards et al., the most frequent site of AM was the LA (64\%). ${ }^{12}$ Furthermore, high recurrence rates (approximately 20\%) have been described. Madson et al. reported that $50 \%$ of patients with $\mathrm{CNC}$-associated $\mathrm{CM}$ undergo two or more surgeries for tumor recurrence than sporadic CM. ${ }^{13}$ The probable causes of recurrence may be related to inadequate resection, totipotent multicentricity, familial type, and metastatic recurrence. ${ }^{14} \mathrm{CM}$ onset can occur at any stage of life, but it is usually diagnosed in the third and

\section{References}

1. Leja MJ, Shah DJ, Reardon MJ. Primary cardiac tumors. Tex Heart Inst J. 2011;38(3):261-2. PMID: 21720466.

2. Garatti A, Nano G, Canziani A, Gagliardotto P, Mossuto E, Frigiola A, et al. Surgical excision of cardiac myxomas: Twenty years experience at a single institution. Ann Thorac Surg. 2012;93(3):825-31. doi: http://dx.doi. org/10.1016/j.athoracsur.2011.11.009

3. Tazelaar HD, Locke TJ, McGregor CG. Pathology of Surgically Excised Primary Cardiac Tumors. Mayo Clin Proc. 1992;67(10):957-65. doi: http:// dx.doi.org/10.1016/S0025-6196(12)60926-4

4. Kamilaris CD, Faucz FR, Voutetakis A, Stratakis CA. Carney Complex. Exp Clin Endocrinol Diabetes. 2019;127(2-3):156-64. doi: 10.1055/a-0753-4943

5. Etxebeste J, Arrillaga M, Basurto J, Gonzalez J, Andraca L, De Salazar AO. Multiple local recurrent myxoma. Echocardiography. 1998;15(3):257-8. doi: 10.1111/j.1540-8175.1998.tb00604.x

6. Manfroi W, Vieira SR, Saadi EK, Saadi J, Alboim C. [Multiple recurrences sixth decades of life and more frequently in women. ${ }^{15}$ Systemic thromboembolism is one of the main clinical characteristics, being observed in $25-50 \%$ of left AM cases. Approximately half of the embolic events mainly involve the central nervous system $^{16}$, corroborating the several cardioembolic events presented in this case report. The standard treatment for $\mathrm{CM}$ in $\mathrm{CNC}$ is surgical resection, which should be performed as soon as the CM diagnosis is confirmed to prevent emboli, obstructive complications, and sudden death. ${ }^{17}$ Adequate resection with clear negative margins is the cornerstone of tumor resection to avoid the risk of recurrence (the tumor should be removed with a tissue margin of $0.5-1 \mathrm{~cm}$ ). Extensive resections may be necessary; in such cases, a remaining interatrial septal defect may be reconstructed with a pericardium patch as in the reported case..$^{18}$ Among CNC patients, approximately $50 \%$ of deaths are attributed to $\mathrm{CM}$ due to sudden death from embolism, stroke, or heart failure. ${ }^{19}$ Early detection through echocardiography is mandatory, becoming an essential tool to establishing an effective treatment.

CM related to familial hereditary syndromes are rare. However, they can cause a wide spectrum of clinical symptoms, including both heart and neurological diseases. Thus, embolic events in young adults should be referred for an echocardiography study to search for an embolic source, namely myxoma. A multidisciplinary approach with surgical intervention by an experienced team is recommended to ensure definitive treatment.

\section{Authors' contributions}

Research conception and design: DAS Jaya, KRP Morales, V Madrini Junior; Data collection: DAS Jaya, KRP Morales; Manuscript writing: DAS Jaya, KRP Morales; Critical review of the manuscript for important intellectual content: $\mathrm{V}$ Madrini Junior, FJA Ramires, PS Gutierrez, RR Dias

\section{Conflict of interest}

The authors have declared that they have no conflict of interest.

of cardiac myxomas with acute tumoral pulmonary embolism]. Arq Bras Cardiol. 2001;77(2):161-6. Portuguese. doi: 10.1590/s0066$782 \times 2001000800007$

7. Mendoza C, Bernstein E, Ferreira A. Multiple recurrences of nonfamilial cardiac myxomas: a report of two cases. Tex Heart Inst]. 2007;34(2):236-9. PMID: 17622378.

8. Li S, Duan L, Wang FD, Lu L, Jin ZY. Carney complex: Two case reports and review of literature. World J Clin Cases. 2018;6(14):800-6. doi: 10.12998/ wjcc.v6.i14.800

9. Moreno Martínez FL, Lagomasino Hidalgo A, Mirabal Rodríguez R, López Bermúdez FH, López Bernal OJ. [Recurrent left atrial myxoma]. Arch Cardiol Mex. 2003;73(4):280-3. Spanish. PMID: 14959453.

10. Ragland MM, Tak T. Detection of atypical right atrial myxoma by echocardiography. Cardiol Rev. 2006;14(2):99-100. doi: 10.1097/01. crd.0000172308.13399.58

11. Shetty Roy AN, Radin M, Sarabi D, Shaoulian E. Familial recurrent atrial 
myxoma: Carney's complex. Clin Cardiol. 2011;34(2):83-6. doi: 10.1002/ clc. 20845

12. Edwards A, Bermudez C, Piwonka G, Berr ML, Zamorano J, Larrain E, et al. Carney's syndrome: complex myxomas. Report of four cases and review of the literature. Cardiovasc Surg. 2002;10(3):264-75. doi: 10.1016/s09672109(01)00144-2

13. Almeida MQ, Villares MC, Mendonça BB. [Carney complex: a case report and literature review]. Arq Bras Endocrinol Metabol. 2004;48(4):544-54. Portuguese. doi: 10.1590/s0004-27302004000400016

14. Shinfeld A, Katsumata T, Westaby S. Recurrent cardiac myxoma: seeding or multifocal disease? Ann Thorac Surg. 1998;66(1):285-8. doi: 10.1016/ s0003-4975(98)00481-0

15. Lima BJ, Andrade AB, Garcia JM, Girodo GA, Reis Filho FA. Presentation of atrial myxoma wiht neurological symptomatology in elderly patient: case report. Rev Médica Minas Gerais. 2020;30(Esp):2019-21.

16. Arauz A, Cantú C, Merlos-Benítez M, Hernández-Curiel B, Barinagarrementeria F, Roldan J. Enfermedad cerebrovascular como complicación de mixoma auricular. Reporte de seis casos y revisión de la literatura. Rev Mex Neurocienc. 2010;11(3):194-8.

17. Wei K, Guo HW, Fan SY, Sun XG, Hu SS. Clinical features and surgical results of cardiac myxoma in Carney complex. J Card Surg. 2019;34(1):14-9. doi: 10.1111/jocs. 13980

18. Yüksel A, Saba D, Velioğlu Y, Ener S, Özkan H. Biatrial approach provides better outcomes in the surgical treatment of cardiac myxomas. Braz J Cardiovasc Surg. 2016;31(4):309-17. doi: 10.5935/1678-9741.20160066

19. Forest AF, Dal Bello F, Schmidt K, Oberger JV, Fernandes JC, Garcia LA, et al. Sporadic Carney complex with testicular tumor and atrial myxoma: case report. Rev Soc Bras Clín Méd. 2015;13(1):61-4. 